\title{
Quantifying Thermal Boundary Condition Details Using a Hybrid Heat Flux Gage
}

\author{
BRIAN Y. LATTIMER, and THOMAS E. DILLER \\ Department of Mechanical Engineering \\ Virginia Tech \\ 203 Randolph Hall (MC0238) \\ Blacksburg, Virginia 24060 USA
}

\begin{abstract}
New methods and experimental techniques were developed in this research to quantify the incident heat flux, absorbed (net) heat flux into a sample, and heat transfer coefficient for samples exposed to mixed mode (radiation and convection) heat transfer typical in fires. Net heat flux into the material was measured at elevated temperatures using a recently developed hybrid heat flux gage, which is both a thermopile type gage as well as a slug calorimeter with an operating temperature $>1000{ }^{\circ} \mathrm{C}$ without cooling. The heat transfer coefficient was determined as a function of time using the hybrid gage output only through a reference state approach. The net heat flux and heat transfer coefficient were then used to calculate a cold surface heat flux and the adiabatic surface temperature. Experiments were performed in the cone calorimeter at different heat fluxes to quantify the incident heat flux, net heat flux, heat transfer coefficient, cold surface heat flux, and adiabatic surface temperature as a function of time. Measured heat transfer coefficients were 9-18 \% different than values calculated using idealized natural convection correlations. The cold surface heat fluxes determined with the hybrid gage were within $5 \%$ of cold surface heat fluxes measured using a water-cooled Schmidt-Boelter heat flux gage.
\end{abstract}

KEYWORDS: heat flux, heat transfer coefficient, adiabatic surface temperature, cone calorimeter, high temperature heat flux gage, hybrid gage.

\section{NOMENCLATURE LISTING}

\begin{tabular}{|c|c|c|c|}
\hline$A_{s}$ & area of exposed surface $\left(\mathrm{m}^{2}\right)$ & $\beta$ & thermal expansion coefficient $\left(\mathrm{K}^{-1}\right)$ \\
\hline$C$ & specific heat capacity $(\mathrm{kJ} / \mathrm{kg} \cdot \mathrm{K})$ & $\delta$ & gage thickness (m) \\
\hline$g$ & gravitational constant $\left(\mathrm{m} / \mathrm{s}^{2}\right)$ & $\varepsilon$ & emissivity (-) \\
\hline$h$ & average heat transfer coefficient $\left(\mathrm{W} / \mathrm{m}^{2} \cdot \mathrm{K}\right)$ & $v$ & kinematic viscosity $\left(\mathrm{m}^{2} / \mathrm{s}\right)$ \\
\hline$k$ & thermal conductivity $(\mathrm{kW} / \mathrm{m} \cdot \mathrm{K})$ & $\rho$ & density $\left(\mathrm{kg} / \mathrm{m}^{3}\right)$ \\
\hline$L$ & length scale of expose surface (m) & $\sigma$ & $\begin{array}{l}\text { Stefan-Boltzman constant } \\
\left(5.67 \times 10^{-11} \mathrm{~kW} / \mathrm{m}^{2} \cdot \mathrm{K}^{4}\right)\end{array}$ \\
\hline$N u_{L}$ & average Nusselt number (-) & \multicolumn{2}{|c|}{ subscripts } \\
\hline$P$ & perimeter of sample (m) & avg & average \\
\hline$q^{\prime \prime}$ & heat flux $\left(\mathrm{kW} / \mathrm{m}^{2}\right)$ & cold & cold surface \\
\hline$R a_{L}$ & Rayleigh number (-) & diff & differential heat flux \\
\hline$S$ & $\begin{array}{l}\text { elevated temperature gage sensitivity } \\
\left(\mathrm{mV} /\left(\mathrm{kW} / \mathrm{m}^{2}\right)\right)\end{array}$ & inc & incident \\
\hline$S_{o}$ & room temperature gage sensitivity $\left(\mathrm{mV} /\left(\mathrm{kW} / \mathrm{m}^{2}\right)\right)$ & net & net into the surface \\
\hline$T$ & temperature $\left({ }^{\circ} \mathrm{C}\right.$ or $\left.\mathrm{K}\right)$ & rad & radiation \\
\hline & time (s) & $s$ & exposed surface \\
\hline \multicolumn{2}{|c|}{ Greek } & $s, a d$ & adiabatic surface \\
\hline$\alpha$ & thermal diffusivity $\left(\mathrm{m}^{2} / \mathrm{s}\right)$ & slug & slug heat flux \\
\hline
\end{tabular}

\section{INTRODUCTION}

Predicting the temperature rise of a material exposed to fire requires knowledge of the thermal boundary condition. Fires produce a mixed mode heat transfer boundary condition that is composed of both convective and radiative heat transfer. Ideally, if the net heat flux into the material (i.e., the heat flux being 
absorbed into the material) were known, then this could be input directly into a thermal model to predict the temperature rise of the material. As pointed out by Wickstrom and Wetterlund [1], the net heat flux into a material is not easily quantified for a variety of reasons including temperature differences between heat flux measuring devices and material surface temperature, emissivity differences between the heat flux device and material surface, gage and surface size differences causing different heat transfer coefficients. As a result, various methods have been developed through the years to quantify the heat transfer boundary condition for use in models. All these methods require knowing the heat transfer coefficient to determine the model boundary condition, but limited work has been performed to quantify the heat transfer coefficient.

The most common method for quantifying the thermal boundary condition for fires is to measure the cold surface heat flux and determine the net heat flux into the material based on the calculated surface temperature. This is done by accounting for the temperature difference between the gage and the material surface. Assuming the gage and material have the same surface emissivity, the net heat flux into the material can be determined from the cold surface heat flux (i.e., the water-cooled gage heat flux) by

$q_{\text {net }}^{\prime \prime}=q_{\text {cold }}^{\prime \prime}-\varepsilon_{s} \sigma\left(T_{s}^{4}-T_{\text {cold }}^{4}\right)-h\left(T_{s}-T_{\text {cold }}\right)$

This requires a surface temperature measurement or model prediction of the surface temperature to determine the net heat flux into the material as well as the heat transfer coefficient. Cold surface heat fluxes are typically measured using water cooled Gardon gages or Schmidt-Boelter thermopile style heat flux gages. Wu [2] also developed a device that uses the change in water temperature along a pipe to determine the heat flux from the fire. These gages have been used to quantify heat fluxes from local fires as well as room fire environments [3]. From Eq. 1, note that the heat transfer coefficient is required to account for the temperature differences between the cold surface and material. As described below, few measurements have been made of the heat transfer coefficient in fires for limited scenarios. Instead, correlations for free and forced convection are typically used to estimate the quantity.

Several indirect methods have been used to quantify the heat flux to cold and hot surfaces. These require inverse heat transfer analysis to be performed to predict the net heat flux onto the device as well as calibration of the device to account for losses. Cylindrical shaped calorimeters have been used by various researchers to quantify heat fluxes from large pool fires to objects [4-6] using inverse heat transfer analysis. References [7-10] have used the temperature rise of steel plates with one insulated side to calculate the absorbed and cold surface heat flux based on one-dimensional inverse heat transfer analysis. Dillon [8] extended this concept to larger plates and used two-dimensional inverse heat transfer on the plates to develop heat flux maps for fires located in the corner of an ISO 9705 fire test room. Cold surface heat fluxes were calculated with assumptions on the heat transfer coefficient. Keltner [9] has used his directional flame thermometer to measure heat flux in various fire applications including furnaces for fire resistance testing. Ingason and Wickstrom [11] have used plate thermometers, which are utilized for furnace control, to predict heat flux from the furnace with some success. In all of these methods, the set-up must be calibrated to account for heat losses through unexposed side of the device which is sometimes a function of the exposure. The heat transfer coefficient at the surface is also required to determine incident heat flux from these devices.

Limited high temperature heat flux gages have been developed and used in fire applications. A high temperature thermopile style gage called a heat flux micro-sensor (HFM) was developed and used in high temperature applications [12] as well as fire [13]. However, this gage is only rated for limited use to about $500^{\circ} \mathrm{C}$. In addition, the gage was not calibrated and used to measure net heat flux into a material surface.

A few studies have attempted to determine the heat transfer coefficient in simple geometries with mixed mode (i.e., convection and radiation) heat transfer. Quintiere and Harkleroad [14] used steady-state surface temperatures on blackened calcium silicate board and incident heat flux levels measured using a watercooled heat flux gage to quantify the heat transfer coefficient in the ASTM E1321 LIFT apparatus [15]. A similar technique was used by Janssens [16] to quantify the heat transfer coefficient in the ASTM E1354 cone calorimeter [17] using calcium silicate. Heat transfer coefficients have also been measured in high speed flows using heat flux measurements and an energy balance at the gage/device surface to quantify the heat transfer coefficient in a purely convective environment with varying gas temperature [18]. 
The adiabatic surface temperature has been proposed as a means for quantifying the thermal boundary condition in radiation dominated environments $[19,20]$. The adiabatic surface temperature is the surface temperature that would exist if the surface where perfectly insulated. By knowing the gas temperature, surface emissivity, and heat transfer coefficient, the adiabatic surface temperature can be determined using a plate thermometer $[19,21]$. The adiabatic surface temperature can then be used as the boundary surface temperature for calculating the thermal response of materials exposed to fire conditions. This technique has been applied to quantify the thermal boundary condition for fire-structural analysis [20,22]. In these calculations, heat transfer coefficients are typically estimated or calculated through natural convection correlation.

The focus of this study is to use a new, novel hybrid heat flux gage to measure the net heat flux into a material surface at elevated temperatures during a mixed mode (convection and radiation) heat transfer exposure. Using the measured net heat flux, a new method was developed to quantify the heat transfer coefficient using a reference state approach. Measurements of net heat flux and heat transfer coefficient were performed in the cone calorimeter at heat fluxes of 8,18 , and $36 \mathrm{~kW} / \mathrm{m}^{2}$. Measured heat transfer coefficients were compared with values calculated using natural convection correlations. With the measured net heat flux and heat transfer coefficient, a cold surface heat flux was calculated and compared with water-cooled heat flux measurements made using a Schmidt-Boelter heat flux gage. In addition, the hybrid gage output as well as the heat transfer coefficient was used to quantify the adiabatic surface temperature as a function of time.

\section{EXPERIMENTAL}

A series of experiments were performed in an ASTM E1354 cone calorimeter to evaluate the efficacy of the hybrid heat flux gage in measuring the elevated temperature net heat flux and the heat transfer coefficient. In addition to experiments using the non-cooled hybrid heat flux gage, experiments were also performed using a Schimdt-Boelter water-cooled heat flux gage. A swing arm assembly was added to the cone calorimeter apparatus to allow for rapid, repeatable placement of the gages beneath the cone heater.

\section{Hybrid Heat Flux Gage}

The hybrid heat flux gage is a device that combines a slug calorimeter with a thermopile differential heat flux gage [23]. The gage, shown in Fig. 1, is constructed of a thermopile fabricated using Type-K thermocouple materials (Chromel and Alumel) and ceramic all contained within an Inconel housing. These thermocouples also provide the surface temperature of the gage. Temperature rise of the gage as well as differential heat flux through the gage are used to determine the net heat flux into the surface that the gage is mounted. The gage housing is $25 \mathrm{~mm} \times 13 \mathrm{~mm} \times 3 \mathrm{~mm}$ thick with the actual sensor part being $9 \mathrm{~mm} \times$ $6 \mathrm{~mm}$, and $3 \mathrm{~mm}$ thick. The gage requires no cooling and has an Inconel sheathed thermocouple wire leads that transmit the signal from the gage to the data acquisition. The gage was coated with high emissivity (0.95) flat black paint.

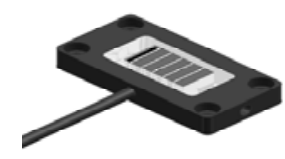

Fig. 1. Hybrid heat flux gage design.

Heat flux gages normally require a good heat sink for proper measurement. Consequently, when they are not water cooled, they need to be mounted on or in a high conductivity material to absorb the thermal energy being transferred through the gage. Unfortunately, there are many situations where this is not possible, particularly in fire testing. Recently, a simple method has been developed specifically to deal with this issue [24]. It uses a hybrid method for obtaining the net heat flux measurements, $q^{\prime \prime}$, by combining both thermopile differential heat flux $\left(q^{\prime \prime}{ }_{\text {diff }}\right)$ with the temporal slug calorimeter heat flux $\left(q^{\prime \prime}\right.$ slug $)$. Using these two components, the result of this analysis showed that the net heat flux could be determined by the following relation

$q^{\prime \prime}=q_{\text {diff }}^{\prime \prime}+\frac{1}{2} q_{\text {slug }}^{\prime \prime}$ 
The slug calorimeter heat flux was determined through the change in the average temperature of the gage, $T_{\text {avg }}$, with respect to time

$q_{s l u g}^{\prime \prime}=\rho C \delta \frac{d T_{a v g}}{d t}$

where $\rho$ is the gage density, $C$ is the gage specific heat capacity and $\delta$ is the gage thickness. The thermal mass of the gage, $\rho C \delta$, is determined through calibration.

This method was validated by performing numerical simulations which were supported by experimentation. With this, the time response and accuracy of hybrid heat flux gage is improved dramatically when mounted on surfaces with any material properties. These gages have been calibrated up to $900{ }^{\circ} \mathrm{C}$ [25] and have operated continuously with the gage temperature up to $1000^{\circ} \mathrm{C}$.

The hybrid heat flux gage was calibrated using a halogen lamp radiation source. In these calibrations, the power to the halogen lamp was controlled using a variable transformer to produce heat fluxes ranging from 5-35 kW/m². A reference Schmidt-Boelter (Medtherm Model No. 64-30SB-20K) water-cooled heat flux gage was used to quantify the heat flux produced at different lamp supplied voltage levels. Lamp voltage levels were measured using a Fluke 177 True RMS Multimeter with a quoted accuracy of $1 \%$ of reading. The hybrid heat flux gage was calibrated to determine the differential heat flux sensitivity at room temperature, high temperature sensitivity, and slug heat flux sensitivity. The differential heat flux calibration results are shown in Fig. 2a with the gage at room temperature. As seen in the figure, the gage response with the gage at room temperature is linear with respect to different radiation levels with a sensitivity of $S_{o}=0.0302 \mathrm{mV} /\left(\mathrm{kW} / \mathrm{m}^{2}\right)$. As the temperature of the sensor increases its response also changes. Through elevated temperature calibration, the gage elevated temperature sensitivity is

$$
S=S_{o}\left(1+3.4923 \times 10^{-4} T+1.0238 \times 10^{-6} T^{2}-3.5056 \times 10^{-9} T^{3}+1.9126 \times 10^{-12} T\right)
$$

where $T$ is the gage temperature $\left({ }^{\circ} \mathrm{C}\right)$. This elevated temperature sensitivity has to do with the change in the Type-K thermocouple materials at elevated temperature. Therefore, the elevated temperature sensitivity does not change from gage to gage. As a result, only a room temperature calibration needs to be performed on the gage to determine $S_{o}$ for Eq .4 to be used to quantify the gage sensitivity at all temperatures.

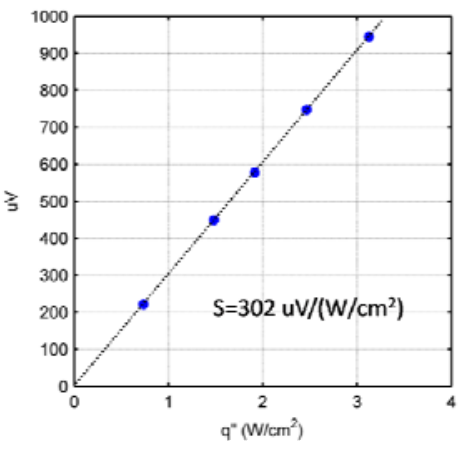

(a)

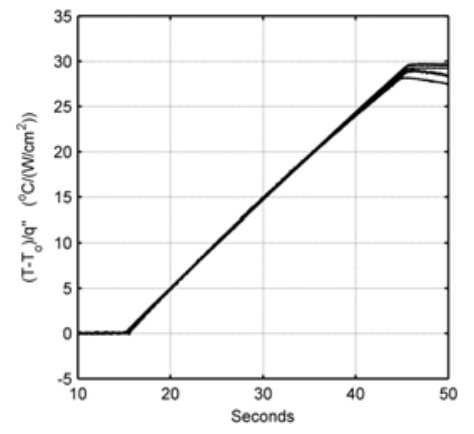

(b)

Fig. 2. Calibration of the: (a) differential; (b) slug calorimeter response of the hybrid heat flux gage.

The thermal mass of the gage, $\rho C \delta$, used to determine the slug calorimeter portion of the heat flux was measured through transient tests on the gage. In this calibration, the sensor was mounted on a thermal insulator and exposed to a short (30 s) heat flux exposure ranging from $5-35 \mathrm{~kW} / \mathrm{m}^{2}$. From these calibration tests, plots of average gage temperature divided by heat flux versus time were produced as shown in Fig. 2b. The linearity in the signal validates the no heat loss assumption implied in Eq. 3 for a slug calorimeter. The slope of this line represents the heat flux gage thermal mass, which was determined to be $10.4 \mathrm{~kW} \cdot \mathrm{s} /\left(\mathrm{m}^{2} \cdot{ }^{\circ} \mathrm{C}\right)$. 


\section{Schmidt-Boelter Heat Flux Gage}

The Schmidt-Boelter thermopile heat flux gage used in this study was a water-cooled, $12.5 \mathrm{~mm}$ diameter gage with a $0-120 \mathrm{~kW} / \mathrm{m}^{2}$ range (Medtherm Model No. GTW-7-32-485A). The gage was coated with high emissivity (0.95) flat black paint. The gage was calibrated using the same halogen radiant source used to calibrate the differential part of the hybrid heat flux gage. The calibration was performed using heat fluxes ranging from $5-35 \mathrm{~kW} / \mathrm{m}^{2}$. Based on the calibration results shown in Fig. 3, the Schmidt-Boelter heat flux gage was determined to have a sensitivity of $0.1795 \mathrm{mV} /\left(\mathrm{kW} / \mathrm{m}^{2}\right)$.

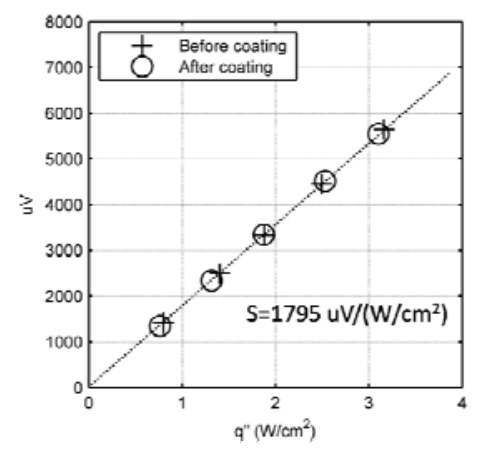

Fig. 3. Calibration results for Schmidt-Boelter heat flux gage.

\section{Cone Calorimeter Experiments}

Heat flux measurements were performed in the cone calorimeter at Virginia Tech. For these experiments, a custom attachment was added onto the set-up that allowed the sample with the embedded heat flux sensor to be rapidly introduced to the heat source in a repeatable fashion. As shown in Fig. 4, a swing arm attachment with a sheet metal sample platform was mounted just outside of the combustion chamber area.

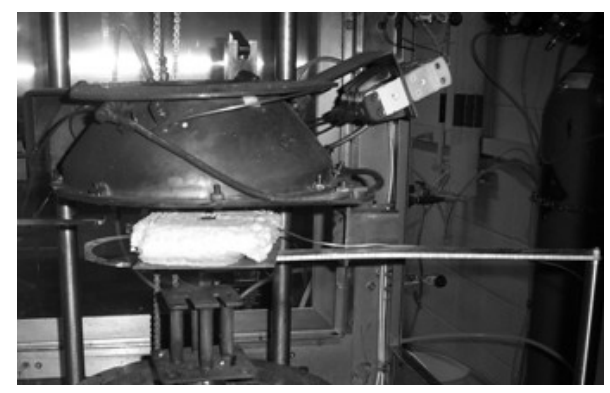

Fig. 4. Experimental set-up in cone calorimeter.

This swing arm was designed so that an ambient baseline heat flux reading could be collected prior to the exposure. At the start of the exposure, the swing arm was rotated until the platform hit a stop that ensured the sample was directly beneath the heater. The sample was exposed to the heat flux until a steady-state was established, which was typically $900 \mathrm{~s}$. During the experiments, the fan on the cone calorimeter was not running to minimize forced convection effects.

Heat flux gages were mounted in ceramic board so that the heat flux gage was flush with the exposed surface of the ceramic board. The ceramic board was fixed onto the metal platform so that the sample did not move during the experiment. During an experiment, only one gage was mounted into the sample board for exposure.

Experiments were performed at cold surface heat fluxes of approximately 7, 18, and $36 \mathrm{~kW} / \mathrm{m}^{2}$. Two experiments were performed with each heat flux gage at every cold surface heat flux tested. Data from the heat flux gages was collected using a computer and National Instruments data acquisition system. 


\section{RESULTS AND DISCUSSION}

Data from the heat flux gage experiments is provided in this section. The heat flux measured using the Schmidt-Boelter gage and hybrid heat flux gage was used to calculate the heat transfer coefficient. In addition, a new novel method is presented on how the hybrid gage alone can be used to quantify the heat transfer coefficient. Using the measured heat transfer coefficient, the hybrid gage is used to predict the cold surface heat flux and adiabatic surface temperature.

\section{Measured Heat Fluxes}

The heat fluxes measured using the Schmidt-Boelter water cooled heat flux gage are provided in Fig. 5 . As seen in this figure, the measured heat fluxes were repeatable within an average standard deviation of less than $2 \%$. The cold surface heat flux during the experiments also remained relatively constant.

Figure 6 contains the heat fluxes measured using the hybrid heat flux gage. These are the net heat flux into the ceramic board with time. Similar to the Schmidt-Boelter heat flux gage results, the differences measured in consecutive tests at the same heat flux was within $2.1 \%$ of the initial cold surface heat flux. As seen in this figure, the heat flux does not remain constant during the experiment like the water cooled gage but instead changes with time. The change in heat flux as a function of time is due to the increase in re-radiation from the gage as the gage surface temperature increases with respect to time, as seen in Fig. 7a.

The measured surface temperature of the hybrid gage and the net heat flux can be used to quantify the incident heat flux onto the gage. The incident heat flux onto the gage is determined from the energy balance on the gage,

$$
q_{\text {net }}^{\prime \prime}=\varepsilon_{s} q_{\text {rad }}^{\prime \prime}+h\left(T_{\infty}-T_{s}\right)-\varepsilon_{s} \sigma T_{s}^{4}
$$

The incident heat flux would be the radiation onto the gage plus the convection, which are the first two terms on the right hand side of Eq. 5. Solving for these terms, the incident heat flux is determined to be

$$
q_{i n c}^{\prime \prime}=\varepsilon_{s} q_{r a d}^{\prime \prime}+h\left(T_{\infty}-T_{s}\right)=q_{n e t}^{\prime \prime}+\varepsilon_{s} \sigma T_{s}^{4}
$$

Incident heat fluxes at the $18 \mathrm{~kW} / \mathrm{m}^{2}$ exposure are provided in Fig. 7b. The incident heat flux is different than the heat flux measured using a cold surface heat flux from a Schmidt-Boelter gage because the convection is different. The cold surface heat flux gage maximizes the convective heat transfer and keeps it constant by maintaining a constant, cold surface temperature. The hybrid gage surface temperature changes with time causing the convection and thus the incident heat flux to also change with time.

Figure 8a contains additional data from the hybrid heat flux gage including the slug calorimeter heat flux, differential heat flux, and total net heat flux. As expected, the slug calorimeter dominates the heat flux response during the early time of the exposure while the differential signal is the majority of the response at longer time periods. It is also of interest to note that the slug calorimeter goes to zero at approximately $600 \mathrm{~s}$ when the heat transfer reaches a steady-state. This is a deficiency of using slug calorimeters; they cannot measure heat flux at steady-state.

A comparison of the net heat flux from the hybrid gage and cold surface heat flux from the SchmidtBoelter gage is provided in Fig. 8b. Results were similar for other heat fluxes. As expected, the heat flux measured early in the exposure is the same for the two devices due to the hybrid gage temperature being close to ambient conditions. As the gage heats up, the net heat flux into the ceramic board decreases until reaching a steady-state value of approximately $1 \mathrm{~kW} / \mathrm{m}^{2}$.

\section{Heat Transfer Coefficient}

A new method was developed to determine the heat transfer coefficient using only the net heat flux measured with the hybrid gage. This method is based on the relation in Eq. 1, which relates a cold surface heat flux to the net heat flux into the material. Equation 1 is solved for the heat transfer coefficient resulting in the following expression 


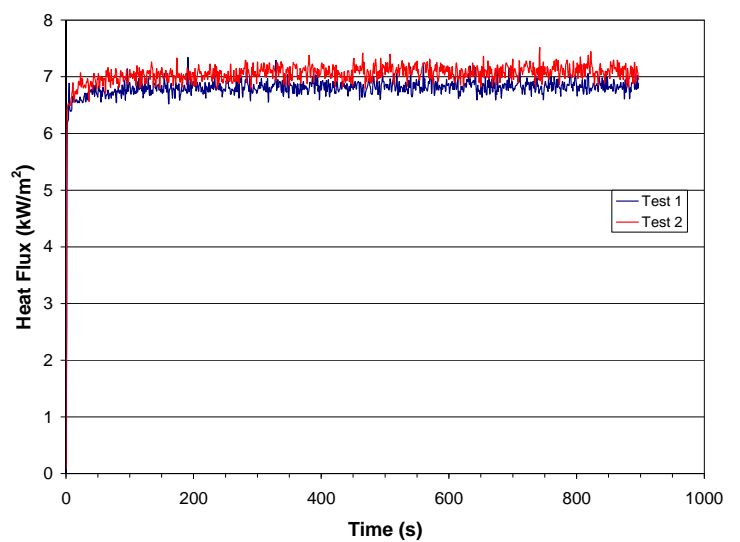

(a)

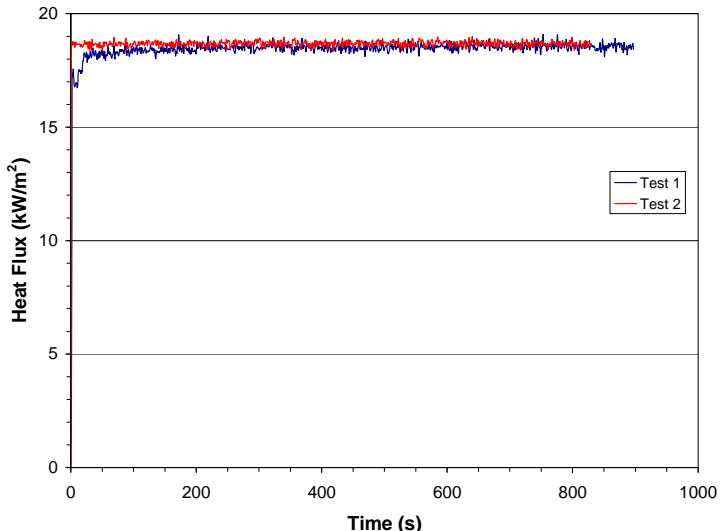

(b)

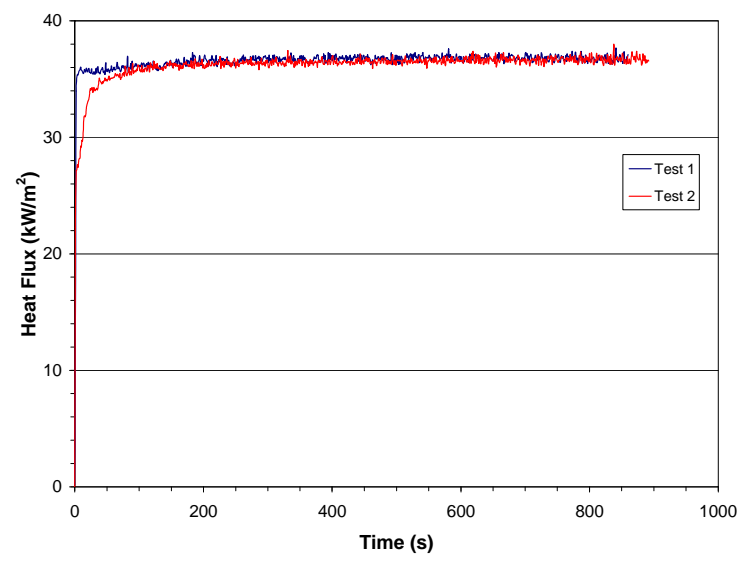

(c)

Fig. 5. Schmidt-Boelter cold surface heat flux measurements at cold surface heat fluxes of: (a) $7 \mathrm{~kW} / \mathrm{m}^{2}$; (b) $18 \mathrm{~kW} / \mathrm{m}^{2}$; (c) $36 \mathrm{~kW} / \mathrm{m}^{2}$.

$h=\frac{\left(q_{\text {cold }}^{\prime \prime}-q_{\text {net }}^{\prime \prime}\right)-\varepsilon_{s} \sigma\left(T_{s}^{4}-T_{\text {cold }}^{4}\right)}{\left(T_{s}-T_{\text {cold }}\right)}$

All of the variables on the right hand side of the equation are measured using the hybrid gage. The net heat flux and surface temperature are the direct outputs from the gage. To determine the cold surface heat flux and temperature, a reference heat flux needs to be established. Based on Fig. 8, the heat flux and temperature in the initial $30 \mathrm{~s}$ of the exposure are equal to the cold surface heat flux measured by a watercooled gage. Therefore, the heat flux during this time period was used as the reference cold surface heat flux and surface temperature. With this reference heat flux and temperature, Eq. 7 was used to quantify the heat transfer coefficient with time.

Results from this analysis are shown in Fig. 9 for the different heat flux levels tested in this research. Each plot shows heat transfer coefficients determined using reference values determined by averaging the heat flux and gage surface temperature over the initial 5, 10, 15, and 20 s periods of the exposure. As seen in the plots, there is no noticeable difference between using any of these reference values. The standard deviation in the heat transfer coefficients determined with the different reference values was $\pm 8-10 \%$ for all exposures. Also included in Fig. 9 are plots of the heat transfer coefficient determined using the coldsurface heat flux measured using the water-cooled Schmidt-Boelter heat flux gage. The standard deviation of the difference between the heat transfer coefficients determined using the hybrid gage only and the hybrid and Schmidt-Boelter gages ranged from $\pm 2-9 \%$ for all exposures. A comparison of average heat transfer coefficients during the steady-state part of the test is provided in Table 1. 


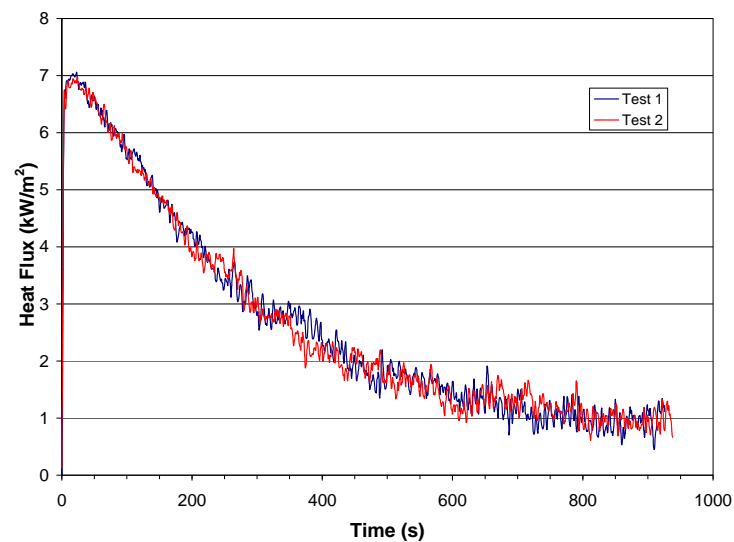

(a)

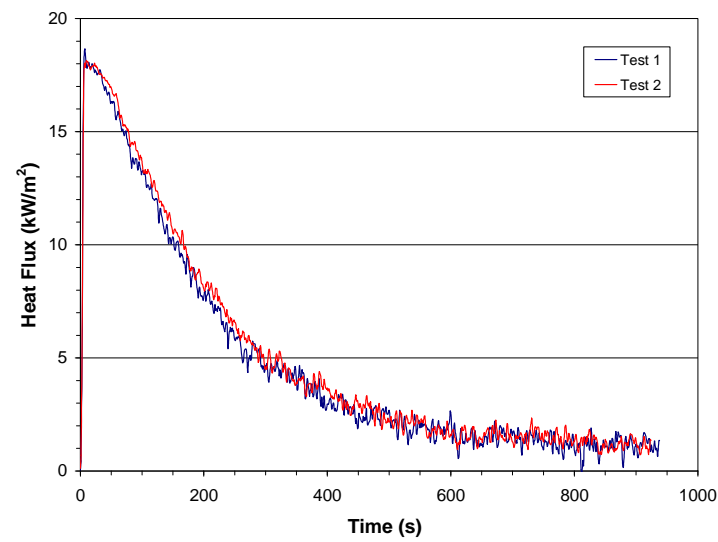

(b)

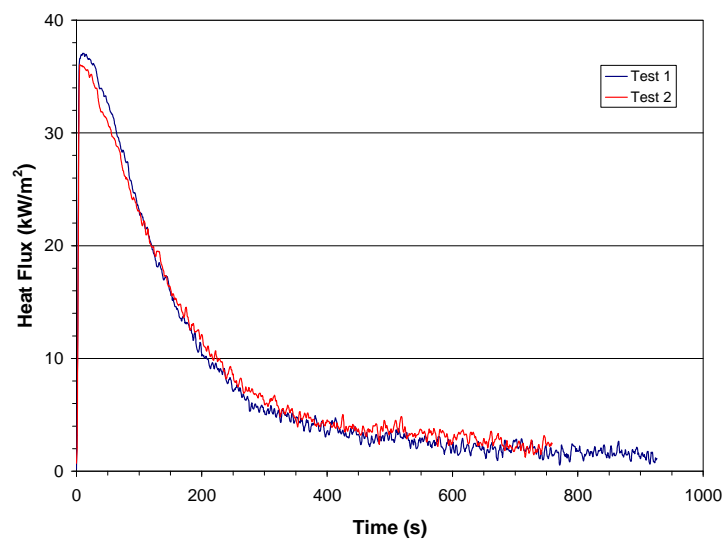

(c)

Fig.6. Hybrid heat flux gage measurements of net heat flux at elevated temperature at cold surface heat fluxes of: (a) $7 \mathrm{~kW} / \mathrm{m}^{2}$; (b) $18 \mathrm{~kW} / \mathrm{m}^{2}$; (c) $36 \mathrm{~kW} / \mathrm{m}^{2}$.

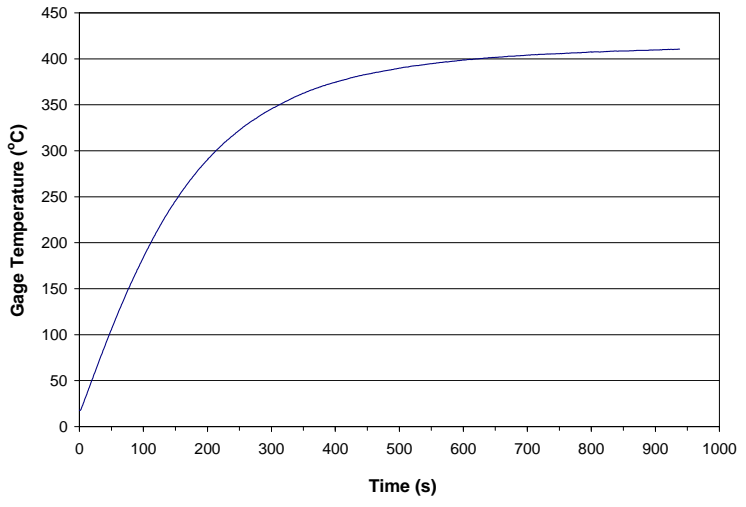

(a)

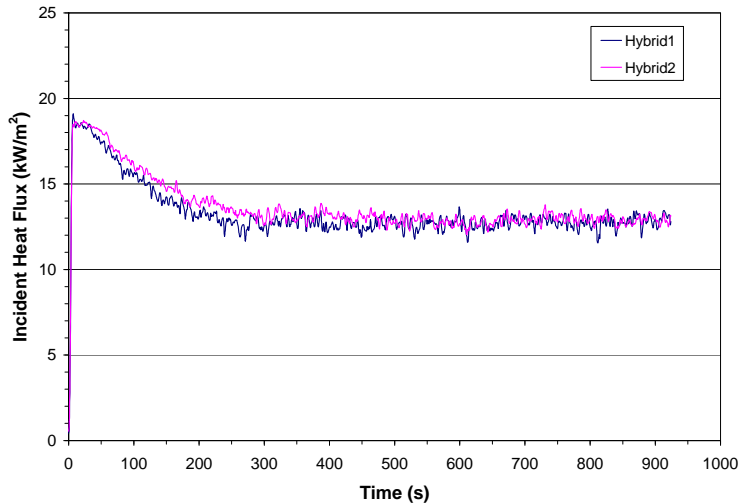

(b)

Fig. 7. (a) Hybrid heat flux surface temperature; (b) Incident heat flux based on hybrid gage measurements. 


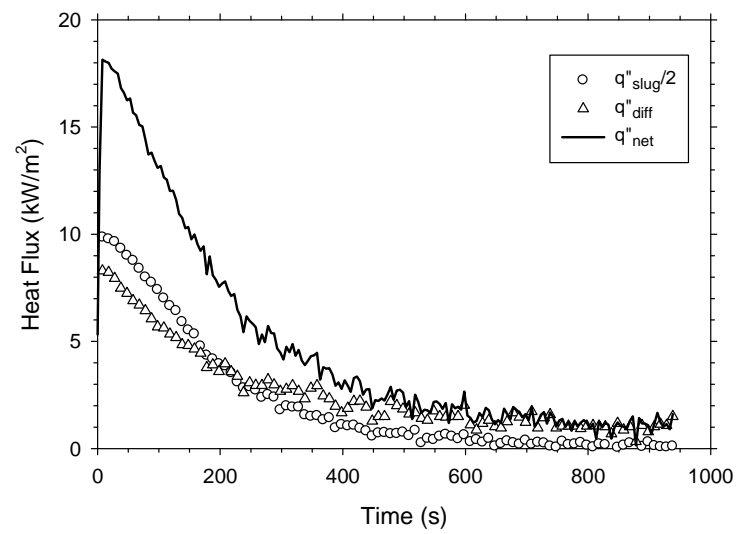

(a)

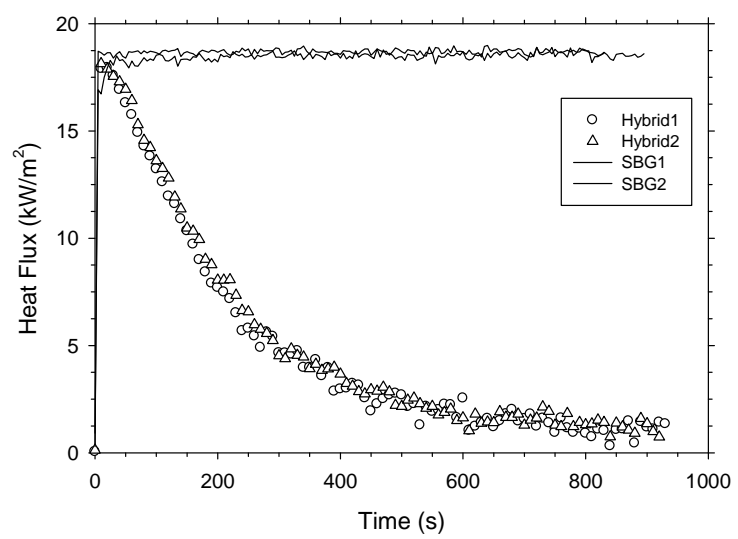

(b)

Fig. 8. Comparison of net heat flux from hybrid gage and cold surface heat flux from Schmidt-Boelter gage at $18 \mathrm{~kW} / \mathrm{m}^{2}$.

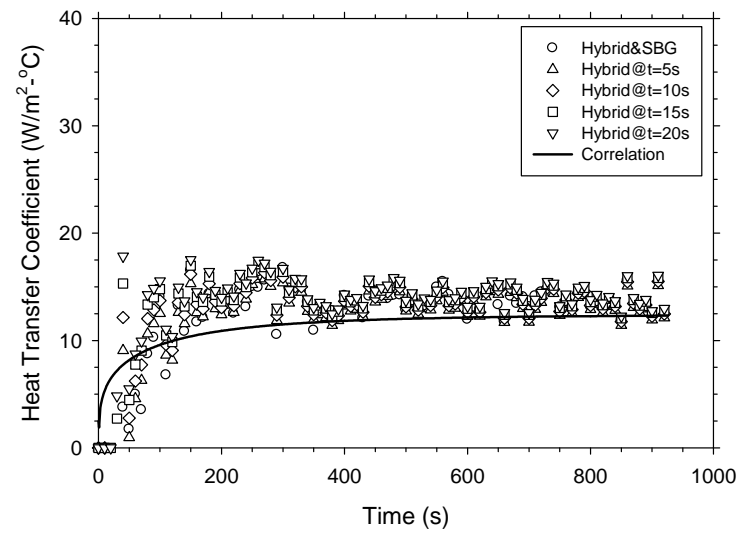

(a)

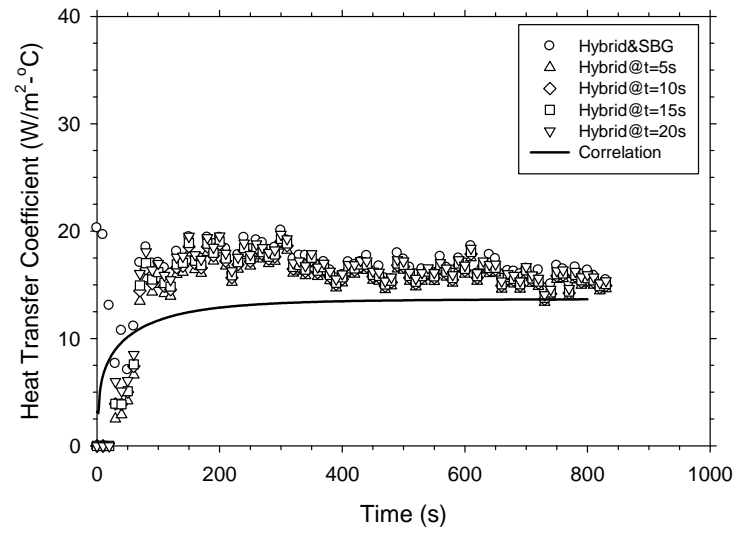

(b)

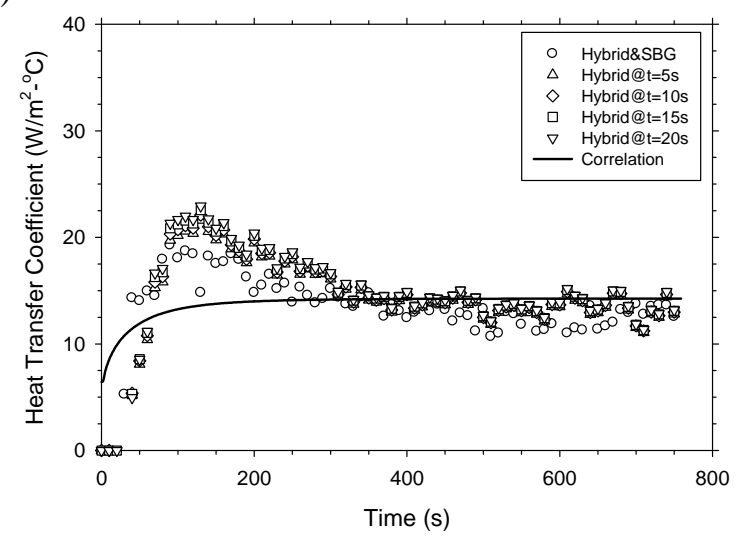

(c)

Fig. 9. Heat transfer coefficient calculated using hybrid gage and Schmidt-Boelter gage at cold surface heat fluxes of: (a) $7 \mathrm{~kW} / \mathrm{m}^{2}$; (b) $18 \mathrm{~kW} / \mathrm{m}^{2}$; (c) $36 \mathrm{~kW} / \mathrm{m}^{2}$.

A common method for estimating the heat transfer coefficient is to use natural convection correlations. For a cone calorimeter sample, the heat transfer coefficient was estimated using an empirical correlation for natural convection on an upward facing constant temperature $\left(T_{s}\right)$, heated horizontal plate that is located in a quiescent, cooler environment at $T_{\infty}$ A similar approach has been used by others [11] but with a different length scale. From Ref. [26], the Nusselt number was calculated by 
Table 1. Average heat transfer coefficients during the steady-state part of the test.

\begin{tabular}{|c|c|c|c|}
\hline \multirow{2}{*}{$\begin{array}{l}\text { Cold surface } \\
\text { heat flux } \\
\left(\mathrm{kW} / \mathrm{m}^{2}\right)\end{array}$} & \multicolumn{2}{|c|}{$\begin{array}{l}\text { Average }^{\mathrm{a}} \text { measured heat transfer } \\
\text { coefficient }\left(\mathrm{W} / \mathrm{m}^{2} \cdot \mathrm{K}\right)\end{array}$} & \multirow{2}{*}{$\begin{array}{c}\text { Average }^{\mathrm{a}} \text { calculated } \\
\text { heat transfer coefficient } \\
\left(\mathrm{W} / \mathrm{m}^{2} \cdot \mathrm{K}\right)\end{array}$} \\
\hline & Method & Value & \\
\hline \multirow{2}{*}{ ( } & Schmidt-Boelter $^{\mathrm{b}}$ & $13.7 \pm 1.1$ & \multirow{2}{*}{12.1} \\
\hline & hybrid $^{\mathrm{c}}$ & $13.9 \pm 1.1$ & \\
\hline \multirow{2}{*}{18} & Schmidt-Boelter $^{\mathrm{b}}$ & $17.0 \pm 1.0$ & \multirow{2}{*}{13.6} \\
\hline & hybrid $^{\mathrm{c}}$ & $16.4 \pm 1.1$ & \\
\hline \multirow{2}{*}{36} & Schmidt-Boelter $^{\mathrm{b}}$ & $13.3 \pm 1.1$ & \multirow{2}{*}{14.1} \\
\hline & hybrid $^{\mathrm{c}}$ & $14.9 \pm 1.4$ & \\
\hline
\end{tabular}

${ }^{\mathrm{a}}$ Averaged over steady state period starting at $300 \mathrm{~s}$.

${ }^{\mathrm{b}}$ Heat transfer coefficient determined using Schmidt-Boelter gage and hybrid gage.

${ }^{\mathrm{c}}$ Heat transfer coefficient determined using hybrid gage only.

$$
N u_{L}=0.54 R a_{L}^{1 / 4}
$$

where

$$
\begin{aligned}
& R a_{L}=\frac{g \beta\left(T_{s}-T_{\infty}\right) L^{3}}{v \alpha} \\
& N u_{L}=\frac{h L}{k}
\end{aligned}
$$

As recommended in Ref. [26], a length scale calculated using the surface area and perimeter of the sample for improved accuracy,

$$
L=A_{s} / P
$$

Properties for Eqs. 9-10 were determined using the film temperature which is the average between the surface temperature and the ambient surroundings temperature, $T_{f}=\left(T_{s}+T_{\infty}\right) / 2$. The ambient surroundings temperature in the laboratory were measured to be $T_{\infty}=293 \mathrm{~K}$ for all tests. Eqs. 8-11 were used to calculate the heat transfer coefficient values provided in Fig. 9. As seen in Fig. 9, the standard deviation of the difference between the measured and calculated heat transfer coefficient ranged from \pm 8-18\%. The difference in the values is attributed to the difference in the convection established in the cone calorimeter compared to that for a heated plate in a quiescent environment, which is the basis for the empirical correlation.

A comparison of the calculated and measured heat transfer coefficients with time is provided in Fig. 9 for the three different heat fluxes tested. For the 7 and $18 \mathrm{~kW} / \mathrm{m}^{2}$ tests, the heat transfer coefficient increased with time during the initial $200 \mathrm{~s}$ of the exposure and then remained at a constant level for the duration of the exposure. This trend is similar to that predicted using the empirical correlation and is attributed to changes in the film temperature with time. In the $36 \mathrm{~kW} / \mathrm{m}^{2}$ experiment, the heat transfer coefficient increases during the initial $150 \mathrm{~s}$ and then decreases to the steady-state heat transfer value. The reason for this more dramatic increase in heat transfer coefficient in the initial part of the exposure is likely due to the more significant convective flow present at these higher heat fluxes in the cone calorimeter set-up, especially when the sample temperature is much different than the conditions around the heater. More detailed flow measurements are required to fully understand the trend.

Table 1 provides a comparison of the average heat transfer coefficient measured and calculated during the steady-state part of the test. The calculated heat transfer coefficients are consistently lower than the calculated values. 


\section{Predicting Cold Surface Heat Flux}

The net heat flux from the hybrid gage can be used to determine the cold surface heat flux. Equation 1 can be rearranged and solved for the cold surface heat flux

$$
q_{\text {cold }}^{\prime \prime}=q_{\text {net }}^{\prime \prime}+\varepsilon_{s} \sigma\left(T_{s}^{4}-T_{\text {cold }}^{4}\right)+h\left(T_{s}-T_{\text {cold }}\right)
$$

The hybrid gage measures the net heat flux as well as the surface temperature and has an emissivity of 0.95 . The cold surface temperature was $T_{\text {cold }}=290 \mathrm{~K}$, which was the water-cooled Schmidt-Boelter heat flux gage temperature. The average time varying heat transfer coefficient measured using the hybrid gage presented in Fig. 9 was used as the heat transfer coefficient in Eq. 12. The predicted cold surface heat flux is provided in Fig. 10 along with the cold surface heat flux measured using the water-cooled Schmidt-Boelter heat flux gage. Cold surface heat fluxes predicted using the hybrid gage were within $\pm 5 \%$ of the water cooled Schmidt-Boelter heat flux measurements.

Being able to predict the cold surface heat fluxes measured using the Schmidt-Boelter gage further verifies that the net heat flux measured with the hybrid gage and the determined heat transfer coefficients are accurate.

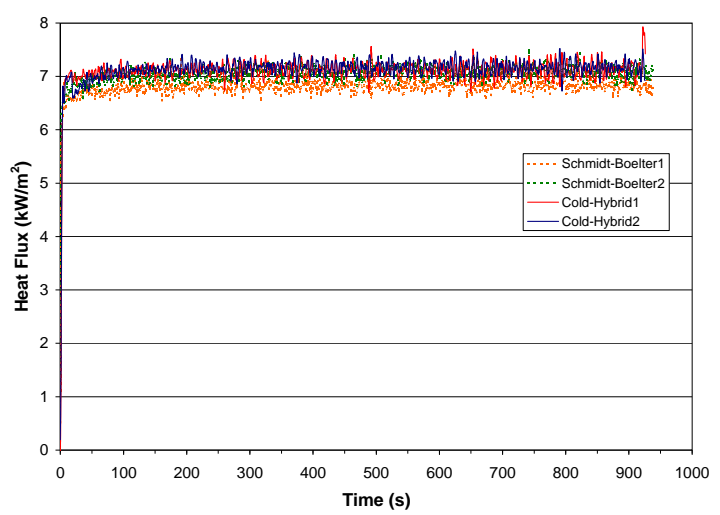

(a)

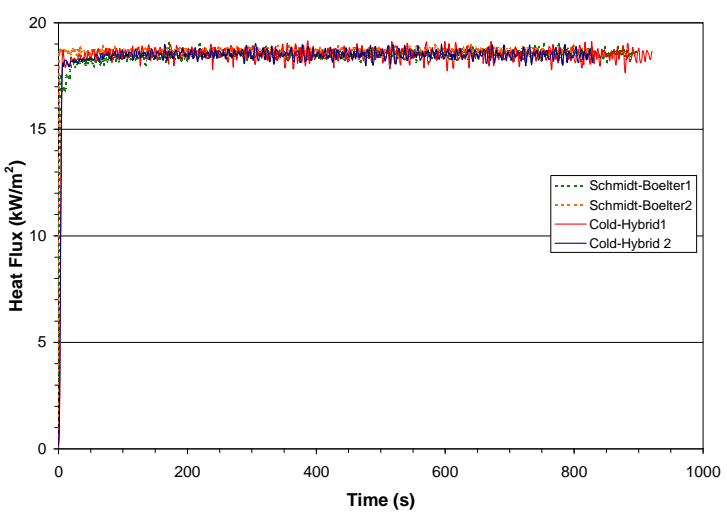

(b)

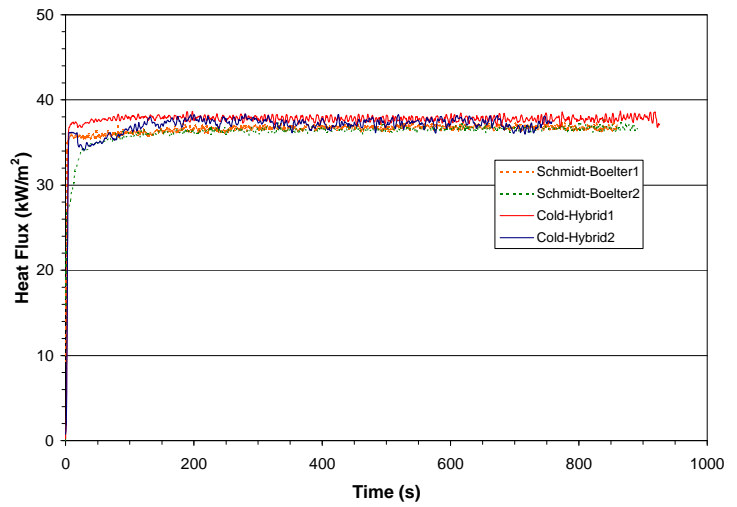

(c)

Fig. 10. Cold surface heat flux calculated from the hybrid gage and measured using the Schmidt-Boelter gage at cold surface heat fluxes of: (a) $7 \mathrm{~kW} / \mathrm{m}^{2}$; (b) $18 \mathrm{~kW} / \mathrm{m}^{2}$; (c) $36 \mathrm{~kW} / \mathrm{m}^{2}$.

\section{Adiabatic Surface Temperature}

The adiabatic surface temperature is the temperature that a surface will reach if the surface is perfectly insulated. References $[19,20]$ have proposed using the adiabatic surface temperature for predicting the heat transfer boundary condition. In particular, the method has been used for structural modeling purposes to provide a more convenient boundary condition for these applications [20,22]. 
The hybrid heat flux gage, along with the heat transfer coefficient determined in a previous section, can be used to determine the adiabatic surface temperature. The heat balance at the surface of the hybrid gage is

$$
q_{n e t}^{\prime \prime}=\varepsilon_{s} q_{\text {rad }}^{\prime \prime}-\varepsilon_{s} \sigma T_{s}^{4}+h\left(T_{\infty}-T_{s}\right)
$$

while, the heat balance at an adiabatic surface exposed to the same conditions is

$$
0=\varepsilon_{s} q_{r a d}^{\prime \prime}-\varepsilon_{s} \sigma T_{s, a d}^{4}+h\left(T_{\infty}-T_{s, a d}\right)
$$

Subtracting Eq. 12 from Eq. 11, the radiation term and convection gas temperature cancel out leaving

$$
q_{n e t}^{\prime \prime}=\varepsilon_{s} \sigma\left(T_{s, a d}^{4}-T_{s}^{4}\right)+h\left(T_{s, a d}-T_{s}\right)
$$

All of the variables in Eq. 15 are known except the adiabatic surface temperature. A nonlinear solver in MATLAB 2008 was used to solve this implicit equation for the adiabatic surface temperature as a function of time. Results of this analysis are provided in Fig. 11.

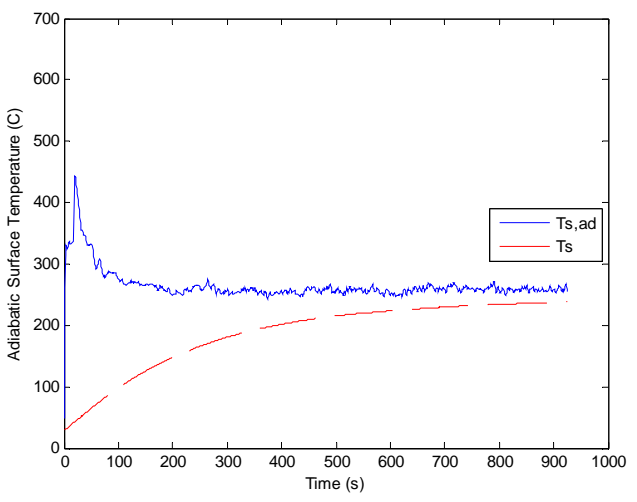

(a)

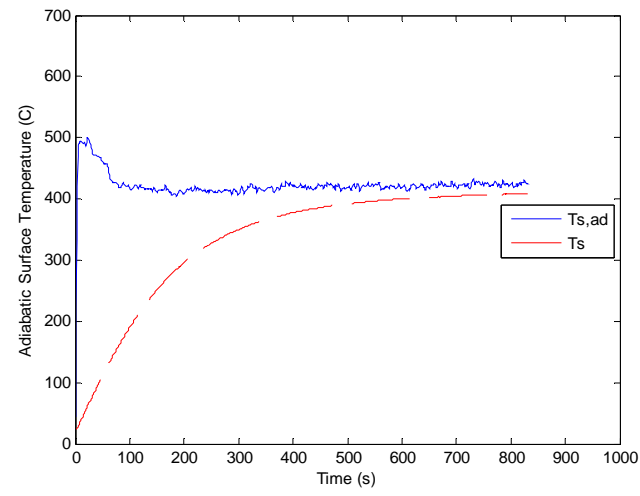

(b)

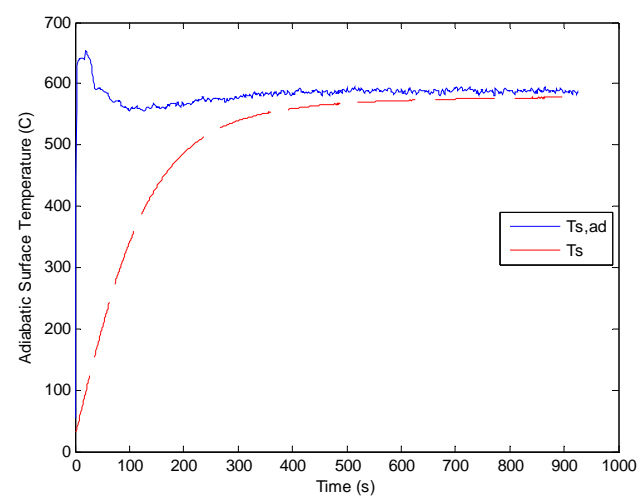

(c)

Fig. 11. Adiabatic surface temperature determined using hybrid gage at cold surface heat fluxes of: (a) $7 \mathrm{~kW} / \mathrm{m}^{2}$; (b) $18 \mathrm{~kW} / \mathrm{m}^{2}$; (c) $36 \mathrm{~kW} / \mathrm{m}^{2}$.

Adiabatic surface temperatures determined at the different heat fluxes are provided in Fig.11 along with the hybrid gage surface temperature. As expected, the adiabatic surface temperature is greater than the gage surface temperature at all times. When the gage goes to steady-state, the adiabatic surface temperature and gage surface temperature converge since the gage is on insulation board. The adiabatic surface temperature is relatively constant during the exposure, except during the initial $100 \mathrm{~s}$ of the exposure. Using the 
adiabatic surface temperature and Eq. 15, the incident heat flux as defined in Eq. 5 can be determined. The incident heat flux calculated using the adiabatic surface temperature is exactly the same as that provided in Fig. $7 \mathrm{~b}$. These results show that the hybrid gage results can also be used to determine the adiabatic surface temperature with time.

\section{SUMMARY AND CONCLUSIONS}

The hybrid heat flux gage has been demonstrated to provide a number of boundary condition details for fire applications including: incident heat flux with time, absorbed (net) heat flux into the sample with time, heat transfer coefficient with time, and the adiabatic surface temperature with time. The measurement of net heat flux into samples using the hybrid gage provides a means for determining these various boundary condition details as well the adiabatic surface temperature. This was demonstrated through a series of heat flux measurements with the hybrid gage in the cone calorimeter on an insulation board. Using the hybrid gage measurements, a method was developed to determine the heat transfer coefficient as a function of time by establishing a reference cold surface heat flux. The heat transfer coefficients measured at various heat fluxes were within \pm 8-18\% of natural convection empirical correlation values. Differences were in part attributed to more complex flow developed in the cone calorimeter apparatus compared to the ideal plate that the natural convection correlations are based upon. With the heat transfer coefficient measured, the cold surface heat flux and adiabatic surface temperature were determined. Cold surface heat fluxes from the hybrid gage were within $\pm 5 \%$ of the water-cooled Schmidt-Boelter heat flux gage, further demonstrating the accuracy of the net heat flux and heat transfer coefficient. Adiabatic surface temperatures were determined with time and were relatively constant at each heat flux except during the initial $100 \mathrm{~s}$ of the exposure. Adiabatic surface temperatures were found to converge with the gage surface temperature as the gage reaches steady-state. The adiabatic surface temperature can be used to calculate the incident heat flux measured using the hybrid gage.

\section{ACKNOWLEDGEMENTS}

The authors would like to thank Mr Brian Dress and Mr Curtis Fox for performing the heat flux experiments. In addition, the assistance that Mr Clay Pullins and Mr David Hubble on the gage calibration is also appreciated.

\section{REFERENCES}

[1] Wickstrom,U. and Wetterlund, I., “Total Heat Flux Cannot Be Measured,” Proceedings of the $10^{\text {th }}$ International Conference on Fire Science and Engineering Interflam, 2004, pp.269-276.

[2] Wu, P.K., 2005. Heat Flux Pipe in Large-scale Fire Tests. Fire Safety Science 8: 1413-1424. http://dx.doi.org/10.3801/IAFSS.FSS.8-1413.

[3] Lattimer, B.Y., "Heat Fluxes from Fires to Surfaces," The SFPE Handbook of Fire Protection Engineering ( $4^{\text {th }}$ Ed.), P.J. DiNenno (ed.), National Fire Protection Association, Quincy, MA, 2007.

[4] Cowley, L.T., "Behaviour of Oil and Gas Fires in the Presence of Confinement and Obstacles," Miscellaneous Report TNMR.91.006, Shell Research Limited, Thornton Research Center, Combustion and Fuels Department, Chester, UK, February, 1991.

[5] Gregory, J.J., Mata, R., and Keltner, N.R., "Thermal Measurements in a Series of Large Pool Fires," Sandia Report Number SAND85-0196, Sandia National Laboratories, NM, 1987.

[6] Russell, L.H. and Canfield, J.A., (1973), Experimental Measurements of Heat Transfer to a Cylinder Immersed in a Large Aviation Fuel Fire, Journal of Heat Transfer, August, pp. 397-404, http://dx.doi.org/10.1115/1.3450070

[7] Ingason, H. and de Ris, J., (1998), Flame Heat Transfer in Storage Geometries, Fire Safety Journal, 31:39-60, http://dx.doi.org/10.1016/S0379-7112(97)00062-3

[8] Dillon, S., 1998, "Analysis of the ISO 907 Room/Corner Test : Simulations, Correlations and Heat Flux Measurements,” NIST-GCR-98-756, NIST, Gaithersburg, MD, August. 
[9] Keltner, N., 2007, "Directional Flame Thermometers - A Tool for Measuring Thermal exposure in furnaces and Improving Control,” Interflam 2007 Conference Proceedings, Interscience, London.

[10] Lennon, P. and Silcock, G., (2001), An Investigation of the Ability of a Thin Plate Heat Flux Device to Determine the Incident Heat Fluxes during Enclosure Fires, International Journal on Engineering Performance-Based Fire Codes, 3(1):1-15.

[11] Ingason, H. and Wickstrom, U., (2007) Measuring Incident Radiant Heat Flux Using the Plate Thermometer, Fire Safety Journal 42(2): 161-166, http://dx.doi.org/10.1016/j.firesaf.\%202006.08.008

[12] Hager, J.M., Onishi, S., Langley, L.W., and Diller, T.E., (1993), "High Temperature Heat Flux Measurements," AIAA Journal of Thermophysics and Heat Transfer 7:531-534.

[13] Lattimer, B.Y., Vandsburger, U., and Langley, L.W., "Detecting Fires Using a Thin-Film Heat Flux Microsensor,” ASME Winter Annual Meeting, Chicago, Illinois, HTD, Vol. 296, November, 1994, pp.137-142.

[14] Quintiere, J. and Harkleroad, M., "New Concepts for Measuring Flame Spread Properties," NBSIR 84-2943, NBS, Gaithersburg, MD, 1984.

[15] ASTM E 1321-97a, "Standard Test Method for Determining Material Ignition and Flame Spread Properties,” 1997 Annual Book of ASTM Standards, Vol. 04.01: Building Seals and Sealants; Fire Standards; Dimension Stone, American Society for Testing and Materials, Philadelphia, PA, pp. 620-635, (1997).

[16] Janssens, M., "Fundamental Thermophysical Characteristics of Wood and Their Role in Enclosure Fire Growth,” Ph.D. Dissertation, University of Gent (Belgium), 1991.

[17] ASTM E1354, "Standard Test Method for Heat and Visible Smoke Release Rate for Materials and Products Using an Oxygen Consumption Calorimeter," 1997 Annual Book of ASTM Standards, Vol. 4.07 Building Seals and Sealants; Fire Standards; Conshohocken, PA, (2000).

[18] Smith, D. E., Bubb, J. V., Popp, O., Grabowski III, H. Diller, T. E., Schetz, J. A., and Ng. W. F., "An Investigation of Heat Transfer in a Film Cooled Transonic Turbine Cascade, Part I: Steady Heat Transfer," ASME Paper 2000-GT-202, 2000.

[19] Wickström, U., 2009. Adiabatic Surface Temperature and the Plate Thermometer for Calculating Heat Transfer and Controlling Fire Resistance Furnaces. Fire Safety Science 9: 1227-1238. http://dx.doi.org/10.3801/IAFSS.FSS.9-1227

[20] Wickstrom, U. Dathinh, D., and McGrattan, K., "Adiabatic Surface Temperature for Calculating Heat Transfer to Fire Exposed Structures," Proceedings of the $11^{\text {th }}$ International Conference on Fire Science and Engineering Interflam, 2007.

[21] Wickstrom, U., The Plate Thermometer-A Simple Instrument for Reaching Harmonized Fire Resistance Tests, Fire Technology 2:195-208, http://dx.doi.org/10.1007/BF01040002

[22] Duthinh, D., McGrattan, K., and Khaskia, A., (2008) Recent Advances in Fire-Structural Analysis, Fire Safety Journal 43:161-167, http://dx.doi.org/10.1016/j.firesaf.2007.06.006

[23] Gifford, A. R., Hubble, D. O., Pullins, C. A., Huxtable, S. T., and Diller T. E., (2010) A Durable Heat Flux Sensor for Extreme Temperature and Heat Flux Environments, AIAA Journal of Thermophysics and Heat Transfer 24: 69-76, http://dx.doi.org/10.2514/1.42298

[24] Hubble, D. O. and Diller, T. E., (2009) A Hybrid Method for Measuring Heat Flux, ASME Journal of Heat Transfer 132:8p, http://dx.doi.org/10.1115/1.4000051

[25] Pullins, C. A. and Diller, T. E., (2010) In situ High Temperature Heat Flux Sensor Calibration, International Journal of Heat and Mass Transfer 53:3429-38, http://dx.doi.org/10.1016/j. ijheatmasstransfer.2010.03.042

[26] Incopera, F. and Dewitt, D., Fundamentals of Heat and Mass Transfer, Third Edition, John Wiley and Sons, New York, 1990. 